\title{
Antioxidant Capacity of Several Romanian Forest Fruits (Rosa canina L., Prunus spinosa L., Vaccium vitis-idaea L. and Cornus mas L.)
}

\section{Luisa ANDRONIE ${ }^{1}$, Liviu HOLONEC ${ }^{2}$, Ioana POP², Alina M. TRUTA², Antonia ODAGIU ${ }^{3}$, Tudor SĂLĂGEAN ${ }^{2}$, Rodica SOBOLU², Aurelia COROIAN ${ }^{1}$, Igori BALTA ${ }^{1}$, Elemer E. ȘUBA ${ }^{2}$}

\author{
${ }^{1}$ University of Agricultural Sciences and Veterinary Medicine, Faculty of Animal Science and Biotechnologies, 3-5 Manastur, Cluj-Napoca, \\ Romania; andronie_luisa@yahoo.com;coroian.aurelia@gmail.com;igori.balta@gmail.com \\ ${ }^{2}$ University of Agricultural Sciences and Veterinary Medicine, Faculty of Horticulture, 3-5 Manastur, Cluj-Napoca, Romania; \\ lholonec@yahoo.com; popioana@usamvcluj.ro; alina_vilcan@yahoo.com (*corresponding author); tudor.salagean@usamvcluj.ro; \\ rodicasobolu@yahoo.com; subaelemeremanuel@gmail.com \\ ${ }^{3}$ University of Agricultural Sciences and Veterinary Medicine, Faculty of Agriculture, 3-5 Manastur, Cluj-Napoca, \\ Romania; antonia.odagiu@usamvcluj.ro
}

\begin{abstract}
The comparison of the antioxidant activity of the studied forest fruits emphasized a hierarchy of the antioxidant capacity in rosehip, blackthorn, lingonberry and cornelian cherry. The purpose of the study was to investigate the antioxidant capacity and nutritional value of rosehip, blackthorn, lingonberry and cornelian cherry. In the current study, the FT-IR spectroscopy technique was applied to detect molecular components in forest fruits samples. Antioxidant capacity was evaluated with photochemical assay as well as humidity, protein, fibre, lipid and carbohydrate content. The FT-IR results revealed the presence of different bio-active compounds in berries such as flavonoids, tannins, sugars, acids, proanthocyanidins, carotenoids, citric metabolites and others. The highest antioxidant capacity was observed in rosehip $105.67 \pm 1.38$ and blackthorn $49.89 \pm 1.92(\mu \mathrm{g} / \mathrm{mg}$ equivalent ascorbic acid). Regarding nutritional parameters, rosehip showed the most increased content of protein displaying average values of 1.60 , carbohydrates 38.20 and fibre 24.10 (g/100 g/sample). These results can provide useful information providing a research interest for the identification of new molecular compounds from Romanian flora samples.
\end{abstract}

Keywords: antioxidants; blackthorn; cornelian cherry; lingonberry; protein; rosehip

\section{Introduction}

Worldwide and from ancient times, traditional medicine played an important role, mainly for the treatment and prevention of various diseases, especially due to the use of active compounds derived from plants (Kinghorn et al., 2011; Newman and Cragg, 2012; De Souza, 2014; Atanasov et al., 2015). A large variety of biologically active substances such as anthocyanins, tannins and polyphenols, which can have a stimulating effect on the growth of probiotic microorganisms either deadly impact the life cycle of pathogenic bacteria, can be derived from plants (Scalbert, 2005; Meydani and Hasan, 2010; Khurana, 2013; Li et al., 2014; Skrovankova et al., 2015; Ozdal et al., 2016).

Essential oils, plant extracts as well as fruit juices play an important role as raw materials in many products such as cosmetics, food industry constituents and medicine.
Moreover, plant based natural products can be used as natural food additives instead of artificial food additives that are considered harmful to human health (Bridle and Timberlake, 1997; Laleh et al., 2006). Furthermore the colourful fruits are considered a major source of antioxidant compounds such as phenolic pigments and anthocyanins that supply multiple beneficial health properties (Seeram $e t$ al., 2001; He et al., 2011).

The anthocyanins are a large subgroup of flavonoids, which are responsible for the production of bright colours from scarlet to blue or red to orange (Khoo et al., 2017). The anthocyanins and the polyphenols derived from forest fruits/berries have recently drawn great attention due to their numerous health-promoting properties acting as free radical scavengers in vivo and in vitro, reducing considerably deleterious effects of free radicals which are mainly generated by reactive oxygen species (Tsuda et al., 2000; 
Heo and Lee, 2005; Ercisli, 2007; Vergani et al., 2018; La Russa et al., 2019). The advantage of using phytochemicals is obvious due to many benefits as reduced toxicity, a wide range of pharmacological actions, rarely manifested side effects and infrequent presence of contraindications (Joseph et al., 2016; Umeno et al., 2016). The lingonberry or mountain cranberry (Vaccinium vitis-idaea L.) is a dwarf shrub from Ericaceae family, native to Europe, Scandinavian countries and Russia (Hokkanen et al., 2009). The entire plant contains a major source of procyanidins, polyphenols, anthocyanidins and flavonols, an abundant class of bioactive compounds found in nature (Bujor et al., 2018). The lingonberry phenolics include simple phenolic acids and flavonoids such as anthocyanins, proanthocyanidins, as well as flavonols that have been suggested to be responsible for many health benefits (Zushang, 2012). The fruits contain both $\mathrm{A}$ and $\mathrm{B}$ type procyanidins as well as a high concentration of oligomers and polymers of flavan-3-ols (Bujor et al., 2018). The procyanidins are known to have potent antioxidant capacities and may reduce the risk of chronic diseases, such as cardiovascular diseases and cancers (Prior and Gu, 2005; Schroeter et al., 2010). Type A procyanidins were suggested to contribute to lingonberries' preventative effects against urinary tract infections becoming the most popular dietary supplement used for the treatment of cystitis in worldwide (Foo et al., 2000; Ercisil, 2007; Kylli et al., 2011; Ștefannescu et al., 2019). The cornelian cherry (Cornus mas L.) is native in Asia and Europe as a slow-growing small tree or large shrub preferring sun or partial shade with well-drained soil. The fruits are rich in anthocyanin, flavonoids, polyphenol, vitamin $\mathrm{C}$ and acids such as ascorbic and loganic that exhibits powerful antioxidant properties and reduce significantly malondialdehyde levels and lipid peroxidation in experimental inflammation (Czerwińska and Melzig, 2018). The mature cornelian cherry fruits and its extracts have been used in traditional medicine for the treatment of gastrointestinal and metabolic disorders (Mamedov and Craker, 2004). Additionally, this fruits possess highly antimicrobial, anticarcinogenic and antidiabetic effects (Radovanović et al., 2013; Milenković-Andjelković et al., 2015; Dinda et al., 2016; Hosseinpour-Jsghdani et al., 2017).

Another European herb is rosehip (Rosa canina L.) from Rosaceae family and their fruits are considered an important source of nutrients (Tumbas et al., 2011). Aside from, the fruits contain high levels of vitamin C, carotenoids (lycopene, beta-carotene, rubixanthin) and polyunsaturated fatty acids (PUFA), which are compounds with elevated antioxidant activity (Angelov et al., 2014; Tumbas et al., 2011). The essential oils from rosehip seeds enclose significant levels of trans-retinoic acid with regenerative properties (Kiralan and Yildirim, 2019). Moreover, these oils exert antibacterial, and anti-inflammatory properties, and could also inhibit cancer cell proliferation (Olsson et al., 2004; Ayati et al., 2018). The seed of cornelian cherry and rosehip contain an important source of vitamins A, B1, B2 and $\mathrm{K}$ and minerals such as $\mathrm{K}, \mathrm{Ca}, \mathrm{Na}, \mathrm{Fe}$ and $\mathrm{Mg}$ (Ozgan, 2002; Dzydzan et al., 2019).

The blackthorn (Prunus spinosa L.), an acid soils herb shrub from Rosaceae family, is native to Europe, Western Asia and Northwest Africa (Aliyazicioglu et al., 2015). The fruits have a rich content of polyphenols, sugars, vitamins, minerals, organic acids, beta-sitosterol, ferulic acid, anthocyanins, prunicyanine, gumiresines and tannins (Veličković et al., 2014; Balta et al., 2019). The fruits present diuretic, astringent, antidysentery and anti-diarrheal effects and they are recommended for gastric problems, kidney affections, dysentery, convulsive cough, diseases of the cardiovascular system and for the stimulation of digestion (Foito et al., 2018).

Global berries such as lingonberry, blackthorn, cornelian cherry, and rosehip are receiving particular attention for their significant content of phenolic compounds and vitamins, which can exhibit a wide range of pharmacological and biological properties such as antimicrobial, antidiabetic, anticancer, renal and hepatoprotective (Lares-Michel et al., 2019).

The fruits of Cornus mas, Prunus spinosa, Rosa canina and Vaccinium vitis-idaea selected in the current study, have a high content in phenolic substances and a high antioxidant capacity which can be used in food and pharmaceutical industries (Brown et al., 2012; Veličković et al., 2014; Dinda et al., 2016; Jimenez et al., 2017). The research interest regarding new sources of antioxidant and anti-inflammatory compounds based on natural products has a major increase. Moreover, experimental studies are necessary for assessments the biological activity of valuable forest fruits and to perform comparative quantifications of their curative properties.

Fourier transform infrared (FT-IR) spectroscopy is one of the most widely used methods to identify chemical compounds and elucidate the chemical structures because is a simple, rapid and accurate method to detect a chemical compound in food products and has a minimum sample preparation requirement (Sharma et al., 2017). This tool has recently been reported to be suitable for application in the pharmaceutical and food industry for the description of polysaccharide - polyphenolic conjugates and other secondary metabolites from plant-based extracts (Liu et al., 2018; Jafarirad et al., 2019; Opris et al., 2019).

Therefore, this work aimed to analyse and to achieve comparisons between molecular structures and antioxidant capacity of rosehip, cornelian cherry, lingonberry and blackthorn fruits dried at room temperature, using vibrational spectroscopic techniques (FT-IR) and in addition antioxidant capacity of lipid-soluble compounds was estimate.

\section{Materials and Methods}

\section{Biologicalmaterial}

The samples were obtained from fresh lingonberry, rosehip, blackthorn and cornelian cherry fruits harvested at full maturity from four sites $\left(1-46^{\circ} 40^{\prime} 54.6^{\prime \prime} \mathrm{N} 23^{\circ} 05^{\prime} 46.1^{\prime \prime} \mathrm{E}\right.$;

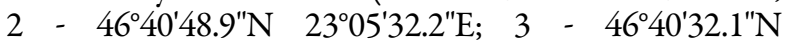
$23^{\circ} 05^{\prime} 48.3^{\prime \prime} \mathrm{E}$; and $\left.4-46^{\circ} 41^{\prime} 19.3^{\prime \prime} \mathrm{N} 23^{\circ} 05^{\prime} 27.2^{\prime \prime} \mathrm{E}\right)$, located in Cluj County, Romania. The fruits were harvested early September and preventively washed with distilled water and then were used for further tests. 
1180

\section{Moisture determination}

The determination of moisture content was evaluated by the air-oven method, according to the methodology previously described by (Kumar and Balasubrahmanyam, 1986) with slightly modifications. The weighted sample was introduced into a vial containing lid and conditioned at 105 ${ }^{\circ} \mathrm{C}$ for at least 45 minutes until a constant mass was obtained and therefore cooled in air-oven. Then 5-10 g of sample is spread uniformly on the entire surface of the vial and weighted with an accuracy of $0.001 \mathrm{~g}$. The humidity content was expressed in percentages.

\section{FT-IR spectroscopy}

The fruit samples (dried at room temperature) were obtained from $3 \mathrm{mg}$ of each fruits used without further purification. FT-IR spectra were performed in the absorbance with a Jasco FT-IR-4100 spectrophotometer using $\mathrm{KBr}$ pellet technique.

The sample was prepared using calcinated potassium bromide as a matrix material and was mixed at a proportion of $3 \mathrm{mg}$ of the sample to $200 \mathrm{mg} \mathrm{KBr}$. Then the mixture was condensed in $15 \mathrm{~mm}$ die at a pressure equal to $10 \mathrm{t}$ till 2 min. The same procedure was applied for the all samples (Crisan et al., 2019)

Measurements were carried out on the infrared scale of $350-4000 \mathrm{~cm}^{-1}$ and a spectral resolution was set at $4 \mathrm{~cm}^{-1}$ and all spectra were acquired over 256 scans. The spectral data were analysed using Origin 6.0 software (Figs. 1-4). These spectra were analysed by comparing the obtained vibrational bands with those of similar functional groups from the literature.

\section{Photochemical assay}

The ACL (Antioxidant Capacity of the Liposoluble Compounds) method previously described by (Hegedus et al., 2010), and slightly modified, was used for estimate the antioxidant capacity. Photochem ${ }^{\circ}$ equipment (Analytik Jena AG, Jena, Germany) was used for measuring the antioxidant capacity. The equipment calibration and measurement of samples are based on the inhibition of free radicals. The amount of antioxidant capacity was achieved by establishing measurement curves that were compared to the measurement curves obtained for the standard solution. The calibration curve principle consists of determining the integrated calibration curve. Data was calculated automatically using a software program called PCL soft.

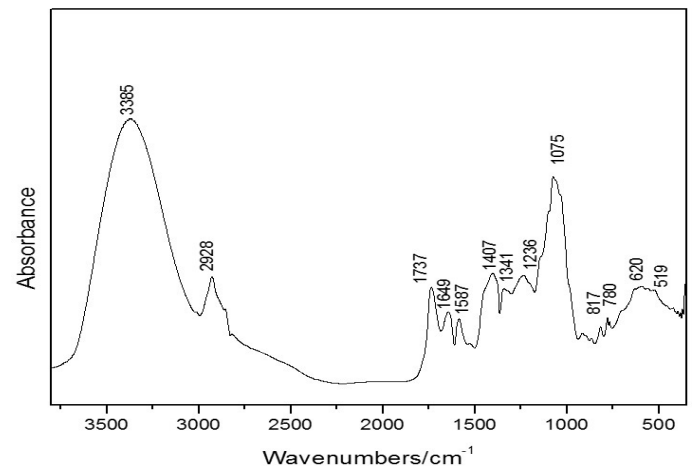

Fig. 1. FT-IR spectrum of lingonberry (Vaccinium vitis-idaea)

\section{Statistical analysis}

The IBM SPSS v.19.0 for Windows, was used for statistical analysis. Basic Statistics, was implemented in order to emphasize the arithmetic mean $(\mathrm{X}) \pm$ standard deviations (SD) of the content of humidity and antioxidant capacity of the studied forest fruits.

The mean concentration of humidity and antioxidant capacity were compared across the various forest fruits using ANOVA followed by Tukey's test. Differences of the means were considered to be significant when p-value < 0.05 .

\section{Results}

\section{FT-IR analysis}

The presence of flavonoids, pectin, proanthocyanidins, tannins, carotenoids, and sugars, fruit acids such as ascorbic acid, malic acid, and citric metabolites which possess antioxidant activity was reported, according to FT-IR analysis.

The analysis revealed that each particular polysaccharide has a specific band, with a maximum detected within 1200$1000 \mathrm{~cm}^{-1}$ region, which is assigned to stretching vibration of $(\mathrm{C}-\mathrm{OH})$ side groups, and the glycoside bond (C-O-C) vibrations in polysaccharide chains, as it can be observed in Figs. 1-4. In this regard the bands identified at $1079 \mathrm{~cm}^{-1}$ (blackthorn), $1077 \mathrm{~cm}^{-1}$ (cornelian cherry), and $1075 \mathrm{~cm}^{-1}$ (lingonberry) specific to this group are more intense in blackthorn, cornelian cherry and lingonberry, compared to rosehip $\left(1079 \mathrm{~cm}^{-1}\right)$. This finding suggested that the rosehip have lower polysaccharide content.

The polyflavonoids showed an intense band at $3385 \mathrm{~cm}^{-}$ ${ }^{1}$ presented in blackthorn, cornelian cherry and lingonberry. The bands with medium intensity identified at $3350 \mathrm{~cm}^{-1}$ were presented in the rosehip spectrum with a specific stretching vibration of $\mathrm{O}-\mathrm{H}$ groups. The absorption bands for the carboxyl group and ester group may be found at $1720-1745 \mathrm{~cm}^{-1}$ (Pancerz et al., 2019), and these groups are presented in all spectra having a high peak in rosehip.

The peak characteristics for asymmetric stretching vibration of- $\mathrm{CH}_{2}$ corresponding to $2924 \mathrm{~cm}^{-1}$ (Santana et al., 2016), and $2853 \mathrm{~cm}^{-1}$ which can be attributed to the stretching vibration of $\mathrm{C}-\mathrm{H}$, are noticeably increasing in rosehip fruits compared to other fruits were this peak was shifted (Fig. 2).

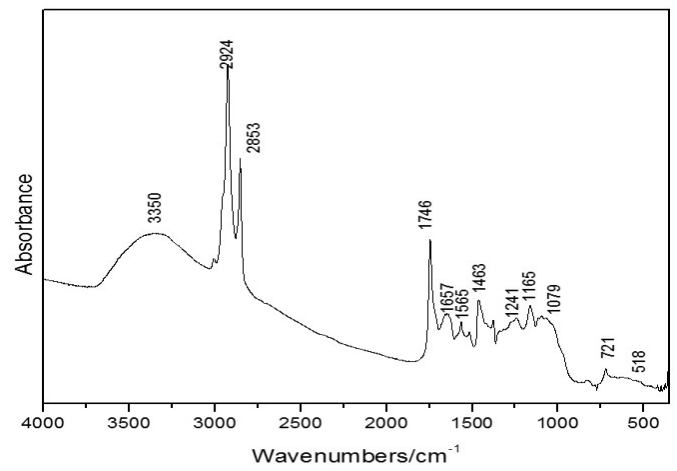

Fig. 2. FT-IR spectrum of rosehip (Rosa canina) 


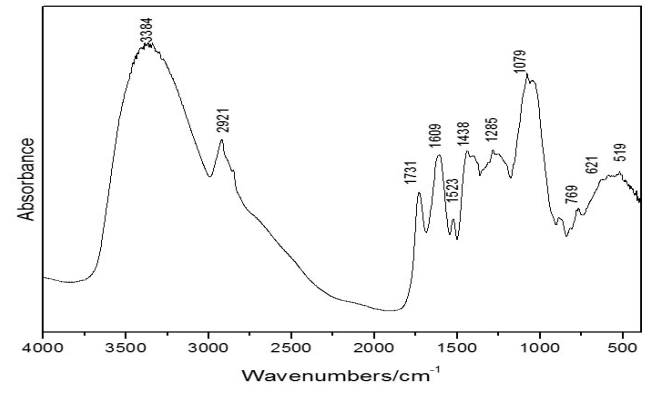

Fig. 3. FT-IR spectrum of blackthorn (Prunus spinosa)

Significant differences between all of the samples (Figs. $1,2,3,4)$ were observed in the area $1750-1550 \mathrm{~cm}^{-1}$, and this corresponds to the oscillation of the carbonyl $\mathrm{C}=\mathrm{O}$ group of fructose and aldehyde $\mathrm{CH}=\mathrm{O}$ of glucose (Saha $e t$ al., 2007; Vardin et al., 2008).

The $1627 \mathrm{~cm}^{-1}$ band is formed due to the stretching vibration of carbonyl group characteristic of the secondary amides and other compounds containing the $\mathrm{C}=0$ group. The band at $1414 \mathrm{~cm}^{-1}$ represents the bending vibrations of $\mathrm{CH}$ indicative of the lignin and this band is more evidenced in cornelian cherry (Fig. 4).

The band located at $1241 \mathrm{~cm}^{-1}$, corresponding to rosehip and cornelian cherry samples, seems to be linked with the presence of ester carbonyl groups. Another interesting region is typically for berries, and it is represented by bands in the range from $890-760 \mathrm{~cm}^{-1}$, which corresponds to the specific oscillation of the anomeric region of carbohydrates, or $\mathrm{C}-\mathrm{H}$ deformation. The region is described by considerable differences between particular samples, in a significant change of bond conformation (glycoside bond) (Samborska et al., 2018). The absorbance of bands at $553-633 \mathrm{~cm}^{-1}$ indicates C-O-O and P-O-C bending of aromatic compounds such as phosphates.

Anthocyanin is an integrated molecule, which assure the transport of electrons through its structure (Cramer $e t$ al., 2011). The absorption peaks of the forest fruits at around $519 \mathrm{~cm}^{-1}$ showed the presence of three anthocyanin pigments (Ramamurthy and Kannan, 2007).

\section{The nutritional quality of the studied forest fruits}

The nutritional values for $100 \mathrm{~g}$ of four types of forest fruits and the characteristic differences among them were present in Table 1.

The rosehip has the highest protein content, while the lowest protein content is reported in lingonberry. In

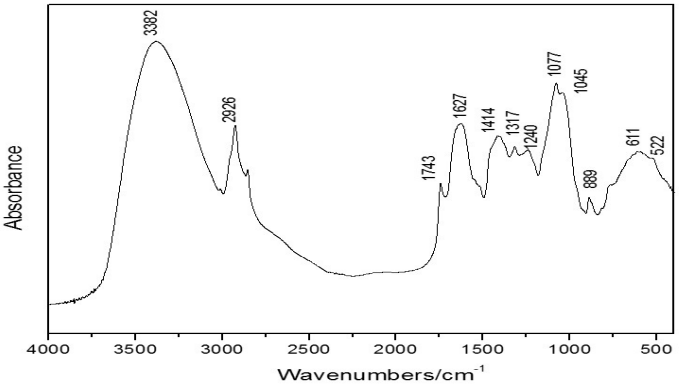

Fig. 4. FT-IR spectrum of cornelian cherry (Cornus mas)

addition, rosehips showed an elevated content of nutritional fibers and carbohydrates. In blackthorn was identified the highest concentration in lipid fraction. The fiber content identified in cornelian cherry was find bellow the limit of detection.

These differences reported in nutritional parameters of the studied forest fruits are the consequence of several reasons, the most relevant being: the species, the variety, and pedo-climatic conditions of culture.

Statistical analysis for the bumidity content and antioxidant capacity

ANOVA analysis was followed by Tukey's test in order to perform multiple comparisons regarding the antioxidant capacity of considered forest fruits.

The Turkey test revealed significant differences between the mean amounts of antioxidants contained respectively in the four categories of forest fruits considered. The results of Turkey's test are displayed in Table 2.

The highest humidity content $74.30 \%$ was identified in cornelian cherry, while the lowest in cranberry, respectively $8.49 \%$. Concerning the antioxidant capacity, the study showed that rosehip assert the highest value (105.67\%), while the lowest values of $34.15 \%$ and $25.15 \%$ are reported for cranberry and cornelian cherry species .

Significant differences, at significance threshold of $0.05 \%$ are reported between the means of the antioxidant capacity of the studied forest fruits species, using Tukey test (Table 3).

Relationships among antioxidant capacity and humidity content of studied fresh forest fruits are emphasized using simple correlations. Significant positive correlations are reported between antioxidant capacity and humidity content in all the analysed samples: rosehip, blackthorn, cranberry, and cornelian cherry.

Table 1. Nutritional parameters of the investigated fruits ( $100 \mathrm{~g} / \mathrm{sample})$

\begin{tabular}{|c|c|c|c|c|c|c|}
\hline Name & Scientific name & Calories & Protein & Lipids & Carbohydrates & Fiber \\
\hline Rosehip & Rosa canina & $162 \mathrm{kcal}$ & $1.60 \mathrm{~g}$ & $0.30 \mathrm{~g}$ & $38.20 \mathrm{~g}$ & $24.10 \mathrm{~g}$ \\
\hline Blackthorn & Prunus spinosa & $57 \mathrm{kcal}$ & $0.75 \mathrm{~g}$ & $1.00 \mathrm{~g}$ & $8.64 \mathrm{~g}$ & $9.00 \mathrm{~g}$ \\
\hline Lingonberry & Vaccium vitis idaea & $46 \mathrm{kcal}$ & $0.46 \mathrm{~g}$ & $0.13 \mathrm{~g}$ & $12.00 \mathrm{~g}$ & $3.60 \mathrm{~g}$ \\
\hline Cornelian cherry & Cornus mas & $76 \mathrm{kcal}$ & $0.70 \mathrm{~g}$ & $0.40 \mathrm{~g}$ & $16.90 \mathrm{~g}$ & $0.00 \mathrm{~g}$ \\
\hline
\end{tabular}

Table 2. The content of humidity and antioxidant capacity of the studied forest fruits

\begin{tabular}{ccc}
\hline Samples & Humidity $(\%)$ & Antioxidant capacity $(\mu \mathrm{g} / \mathrm{mg}$ equivalent ascorbic acid $)$ \\
\hline Rosehip & $30.30 \pm 1.17$ & $105.67 \pm 1.38$ \\
Blackthorn & $54.85 \pm 2.11$ & $49.89 \pm 1.92$ \\
Cranberry & $8.49 \pm 1.18$ & $34.15 \pm 1.82$ \\
Cornelian cherry & $74.30 \pm 2.10$ & $25.15 \pm 1.65$ \\
\hline
\end{tabular}


1182

Table 3. The differences and significance of differences concerning antioxidant capacity of the studied forest fruits (Tukey test)

\begin{tabular}{|c|c|c|c|c|}
\hline & Rosehip & Blackthorn & Cranberry & Cornelian cherry \\
\hline Rosehip & - & $72.92^{*}$ & $93.42^{*}$ & $105.19^{*}$ \\
\hline Blackthorn & & - & $20.55^{*}$ & $32.35^{*}$ \\
\hline Cranberry & & & - & $11.77^{*}$ \\
\hline
\end{tabular}

Table 4. The correlation coefficients between antioxidant capacity and humidity content of the studied forest fruits

\begin{tabular}{ccccc}
\hline Antioxidant capacity $(\mu \mathrm{g} / \mathrm{mg}$ equivalent ascorbic acid) & Rosehip & Blackthorn & Lingonberry & Cornelian cherry \\
\hline Rosehip humidity $(\%)$ & $0.98^{*}$ & - & - & - \\
Blackthorn humidity $(\%)$ & - & $0.91^{*}$ & - & - \\
Cranberry humidity $(\%)$ & - & - & $0.96^{*}$ & - \\
Cornelian cherry humidity $(\%)$ & - & - & - & $0.95^{*}$ \\
\hline
\end{tabular}

Note: ${ }^{*}$ Correlation is significant at $\mathrm{p}<0.05$.

A great correlation is identified between the mean humidity content in rosehip and antioxidant capacity, with a positive correlation coefficient of $0.98(\mu \mathrm{g} / \mathrm{mg}$ equivalent ascorbic acid) while the lowest interaction, is identified in blackthorn, with a correlation coefficient of 0.91 (Table 4).

\section{Conclusions}

The resulted data revealed that the rosehip and blackthorn have the highest antioxidant capacity and the lowest antioxidant capacity was noticed in cornelian cherry. Moreover, the most increased nutritional indices were observed in rosehip and blackthorn. In conclusion, berries samples from Romania flora exhibit antioxidant capacity and more investigations should be performed on this topic to describe the complex interactions among antioxidants and the human body. It is promising to observe that molecular compounds, such as those in rosehip, blackthorn, lingonberry and cornelian cherry, may provide a potential interest in food and pharmaceutical research.

\section{Acknowledgements}

This project is funded by the Ministry of Research and Innovation through Program 1 - Development of the National Research and Development System, Subprogram 1.2 - Institutional Performance - Projects for Financing the Excellence in CDI, Contract no. 37PFE/06.11.2018. Title of the project: "Increasing the institutional performance through consolidation and development of research directions within the USAMVCN".

\section{Conflict of Interest}

The authors declare that there are no conflicts of interest related to this article.

\section{References}

Aliyazicioglu R, Yildiz O, Sahin H, Eyuboglu OE, Ozkan MT, Karaoglu SA, Kolayliali S (2015). Components and antioxidant activity of Prunus spinosa from Gumushane, Turkey. Chemistry of Natural Compounds 51(2):346-349.
Angelov G, Boyadzhieva SS, Georgieva SS (2014). Rosehip extraction: process optimization. Central European Journal of Chemistry 12(4):502-508.

Atanasov AG, Waltenberger B, Pferschy-Wenzig EV, Linder T, Wawrosch C, Uhrin P, ... Stuppner H (2015). Discovery and resupply of pharmacologically active plant-derived natural products: a review. Biotechnology Advances 33(8):1582-1614.

Ayati Z, Amiri MS, Ramezani M, Emami A (2018). Traditional uses and pharmacological profile of rose hip: a review. Current Pharmaceutical Design 24(35):1-24.

Balta I, Sevastre B, Miresan V, Taulescu M, Raducu C, Longodor AL, Coroian A (2019). Protective effect of blackthorn fruits (Prunusspinosa) against tartrazine toxicity development in albino Wistar rats. BMC Chemistry 13(1):104.

Bridle P, Timberlake CF (1997). Anthocyanins as natural food coloursselected aspects. Food Chemistry 58(1):103-109.

Brown PN, Turi CE, Shipley PR, Murch SJ (2012). Comparisons of large (Vaccinium macrocarpon Ait.) and small (Vacinium oxycoccos L., Vacinium vitis-idaea L.) cranberry in British Columbia by phytochemical determination, antioxidant potential, and metabolomic profiling with chemometric analysis. Planta Medica 78(6):630-640.

Bujor OC, Ginies C, Popa VI, Dufour C (2018). Phenolic compounds and antioxidant activity of lingonberry (Vaccinium vitis-idaea $\mathrm{L}$.) leaf, stem and fruit at different harvest periods. Food Chemistry 252:356-365.

Cramer H, Choi D, Griep M, Karna SP (2011). Anthocyanin dyes in titanium dioxide nanoparticle-dye sensitized solar cells. 11th IEEE International Conference on Nanotechnology, Portland pp 684686.

Crișan I, Vidican R, Olar L, Stoian V, Morea A, Ștefan R (2019). Screening for changes on Iris germanica L. rhizomes following inoculation with arbuscular mycorrhiza using Fourier transform infrared spectroscopy. Agronomy 9(12):815.

Czerwińska ME, Melzig MF (2018). Cornus mas and Cornus officinalisanalogies and differences of two medicinal plants traditionally used. Frontiers in Pharmacology 9:894.

De Souza VR, Pereira PA, da Silva TL, de Oliveira Lima LC, Pio R, Queiroz F (2014). Determination of the bioactive compounds, antioxidant activity and chemical composition of Brazilian blackberry, red raspberry, strawberry, blueberry and sweet cherry fruits. Food Chemistry 156:362368. 
Dinda B, Kyriakopoulos AM, Dinda S, Dinda M (2016). Cornus mas L. (Cornelian cherry), an important European and Asian traditional food and medicine: ethnomedicine, phytochemistry and pharmacology for its commercial utilization in drug industry. Journal of Ethnopharmacology 193:670-690.

Dzydzan O, Bila I, Kucharska AZ, Brodyak I, Sybirna N (2019). Antidiabetic effects of extracts of red and yellow fruits of cornelian cherries (Cornus mas L.) on rats with streptozotocin-induced diabetes mellitus. Food and Function 10(10):6459-6472.

Ercisli S (2007). Chemical composition of fruits in some rose (Rosa spp) species. Food Chemistry 104(4):1379-1384.

Foito A, McDougall GJ, Stewart D (2018). Evidence for health benefits of berries. Annual Plant Reviews 15:143.

Foo LY, Lu Y, Howell AB, Vorsa N (2000). The structure of cranberry proanthocyanidins which inhibit adherence of uropathogenic Pfimbriated Escherichia coli in vitro. Phytochemistry 54(2):173-181.

He K, Li X, Chen X, Ye X,HuangJ,Jin Y,... Shu H (2011).Evaluation of antidiabetic potential of selected traditional Chinese medicines in STZinduced diabetic mice. Journal of Ethnopharmacology 137(3):11351142.

Hegedus A, Engel R, Sefanovits-Banyai E (2010). Antioxidant and antiradical capacities in apricot (Prunus armeniaca L.) fruits: variations from genotypes, years, and analytical methods. Journal of Food Science 75(9):C722-C730.

Heo HJ, Lee CY (2005). Strawberry and its anthocyanins reduce oxidative stress-induced apoptosis in PC12 cells. Journal of Agricultural and Food Chemistry 53(5):1984-1989.

Hokkanen J, Mattila S, Jaakola L, Tolonen A (2009). Identification of phenolic compounds from lingonberry (Vacinium vitis-idaea L.), bilberry (Vaccinium myrtillus L.) and hybrid bilberry (Vacinium $x$ intermedium Ruthe L.) leaves. Journal of Agricultural and Food Chemistry 57:9437-9447.

Hosseinpour-Jsghdani F, Gholipour-Shahraki S, Rahimi-Madiseh M, Rafieian-Kopae M (2017). Cornus mas a review on traditional uses and pharmacolohgical properties. Journal of Complementary and Integrative Medicine 14(3):1-28.

Jafarirad S, Salmasi J, Divband B, Sarabchi M (2019). Systematic study of $\mathrm{Nd} 3+$ on structural properties of $\mathrm{ZnO}$ nanocomposite for biomedical applications; in-vitro biocompatibility, bioactivity, photoluminescence and antioxidant properties. Journal of Rare Earths 37(5):508-514.

Jiménez S, Jiménez-Moreno N, Luquin A, Laguna M, Rodríguez-Yoldi MJ, Ancín-Azpilicueta C (2017). Chemical composition of rosehips from different Rosa species: an alternative source of antioxidants for the food industry. Food Additives \& Contaminants: Part A 34(7):1121-1130.

Joseph SV, Edirisnghe I, Burton-Freeman B (2016). Fruit polyphenols: a review of anti-inflammatory effects in humans. Critical Reviews in Food Science and Nutrition 56(3):419-444.

Khoo HE, Azlan A, Teng Tang S, Lim SM (2017). Anthocyanidins and anthocyanins: colored pigments as food, pharmaceutical ingredients, and the potential health benefits. Food and Nutrition Research 61(1):1361779.

Khurana S, Venkataraman K, Hollingsworth A, Piche M, Tai TC (2013). Polyphenols: benefits to the cardiovascular system in health and in ageing. Nutrients 5:3779-3827.

Kinghorn AD, Pan L, Fletcher JN, Chai H (2011). The relevance of higher plants in lead compound discovery programs. Journal of Natural Products 74:1539-1555.

Kiralan M, Yildirim G (2019). Rosehip (Rosa canina L.) oil. In: Ramadan M (Ed). Fruit oils: chemistry and functionality. Springer,Egypt pp 803-814.

Kumar KR, Balasubrahmanyam N (1986). Moisture sorption and the applicability of the Brunauer-Emmett-Teller equation for some dry food products. Journal of Stored Products Research 22(4):205-209.

Kylli P, Nohynek L, Puupponen-Pimiä R, Westerlund-Wikström B, Leppänen T, Welling J, ... Heinonen M (2011). Lingonberry (Vaccinium vitis-idaea) and European Cranberry (Vacinium microcarpon) proanthocyanidins: Isolation, identification, and bioactivities. Journal of Agricultural and Food Chemistry 59(7):337384.

La Russa D, Giordano F, Marrone A, Parfati M, Janda E, Pellegrino D (2019). Oxidative imbalance and kidney damage in cafeteria dietinduced rat model of metabolic syndrome: effect of bergamot polyphenolic fraction. Antioxidants 8(3): 66 .

Laleh GH, Frydoonfar H, Heidary R, Jemeei R, Zare S (2006). The effect of light, temperature, $\mathrm{pH}$ and species on stability of anthocyanin pigments in four Berberis species. Pakistan Journal of Nutrition 5(1):90-21.

Lares-Michel M, Housni FE, Cervantes VGA, Cañedo CL (2019). Influence of women age on berries consumption: the role of liking and properties of berries as determinants of their intake. Food Science and Nutrition Studies 3(1).

Li AN, Li S, Zhang YJ, Xu XR, Chen YM, Li H (2014). Resources and biological activities of natural polyphenols. Nutrients 6:6020-6047.

Liu J, Bai R, Liu Y, Zhang X, Kan J, Jin K (2018). Isolation, structural characterization and bioactivities of naturally occurring polysaccharidepolyphenolic conjugates from medicinal plants-a reivew. International Journal of Biological Macromolecules 107:2242-2250.

Mamedov N, Craker LE (2004). Cornelian cherry: a prospective source for phytomedicine. Acta Horticulturae 629:83-87.

Meydani M, Hasan ST (2010). Dietary polyphenols and obesity. Nutrients 2:737-751.

Milenković-Andjelković AS, Andjelković MZ, Radovanović AN, Radovanović BC, Nikolić V (2015). Phenol composition, DPPH radical scavenging and antimicrobial activity of Cornelian cherry (Cornusmas) fruit and leaf extracts. Hemijska Industrija 69(4):331-337.

Newman DJ, Cragg GM (2012). Natural products as sources of new drugs over the 30 years from 1981 to 2010.Journal of Natural Products 75:311-335.

Olsson ME, Gustavsson KE, Andersson S, Nilsson A, Duan RD (2004). Inhibition of cancer cell proliferation in vitro by fruit and berry extracts and correlation with antioxidant levels. Journal of Agriculture and Food Chemistry52(24):72647271.

Opris R, Toma V, Olteanu D, Filip GA (2019). Effects of silver nanoparticles functionalized with Cornus mas L. extract on architecture and apoptosis in rat testicle. Nanomedicine 14(3):275-299.

Ozdal T, David A Sela, XiaoJ, Boyacioglu D, Chen F, Capanoglu E(2016). The reciprocal interactions between polyphenols and gut microbiota and effects on bioaccessibility. Nutrients 8(2):78. 
1184

Ozgan M (2002). Nutrient composition of rose (Rosa canina L.) seed and oils.Journal of Medicinal Food 5(3):137-40.

Pancerz M, Ptaszek A, Sofiniska K, Barbasz J, Szlachcic P, Kucharek M, Lukasiewicz M (2019). Colligative and hydrodynamic properties of aqueous solutions of pectin from cornelian cherry and commercial apple pectin. Food Hydrocolloids 89:406-415.

Prior RL, Gu L (2005). Occurrence and biological significance of proanthocyanidoins in the American diet. Phytochemistry 66(18):2264-2280.

Radovanović BC, Anđelković SM, Radovanović AB, Anđelković MZ (2013). Antioxidant and antimicrobial activity of polyphenol extracts from wild berry fruits grown in Southeast Serbia. Tropical Journal of Pharmaceutical Research 12(5):813-819.

Ramamurthy N, Kannan S (2007). Fourier transforms infrared spectroscopic analysis of a plant (Calotropis gigantea linn) from an industrial village, Cuddalore dt, Tamilnadu, India. Romanian Journal of Biophysics 17(4):269-276.

Saha NK, Balakrishnan M, Ulbricht M (2007). Sugarcane juice ultrafittration: FTIR and SEM analysis of polysaccharide fouling. Journal of MembraneScience 306(1-2):287-297.

Samborska K, Kaminska P, Jedlinska A, Matwijczuk A, KaminskaDwórznicka A (2018). Membrane processing in the sustainable production of low-sugar apple-cranberrry cloudy juice. Applied Sciences $8(7): 1082$.

Santana FB, Gontijo LC, Mitsutake H, Mazivilla SJ, Sourza LM, Borges W (2016). Non-distructive fraud detection in rosehip oil by MIR spectroscopy and chemimettrics. Food Chemistry 33:209:228.

Scalbert A, Manach C, Morand C, Remesy C, Jimenez L (2005). Dietary polyphenols and the prevention of diseases. Critical Reviews in Food Science and Nutrition 45:287-306.

Schroeter H, Heiss C, Schmitz HH (2010). Recommending flavanols and procyanidins for cardiovascular health: current knowledge and future needs. Molecular Aspects of Medicine 31(6):546-557.
Seeram NP, Momin RA, Nair MG, Bourquin LD (2001). Cyclooxygenase inhibitory and antioxidant cyanidin gycosides in cherries and berries. Phytomedicine 8(5):362-369.

Sharma S, Srivastava S, Singh R, Uttam KN (2017). Label-free and rapid spectroscopic evaluation of ripening of Syzygium cumini fruit. SpectroscopyLetters 50(2):115-123.

Skrovankova S, Sumczynski D, Mlcek J, Jurikova T, Sochor J (2015). Bioactive compounds and antioxidant activity in different types of berries. International Journal of Molecular Sciences 16(10):2467324706.

Ștefănescu BE, Szabo K, Mocan A, Crişan G (2019). Phenolic compounds from five Ericaceae species leaves and their related bioavailability and health benefits. Molecules 24(11):2046.

Tsuda T, Horio F, Osawa T (2000). The role of anthocyanins as an antioxidant under oxidative stress in rats. Biofactors 13(1-4):133-139.

Tumbas VT, Canadanović-Brunet JM, Cetojević-Simin DD, Cetković GS, Ethilas SM, Gille L (2011). Effect of rosehip (Rosa canina L.) phytochemicals on stable free radicals and human cancer cells. Journal of the Science of Food and Agriculture 92:1273-1281.

Umeno A, Horie M, Murotomi K, Nakajima Y, Yoshida Y (2016). Antioxidative and antidiabetic effects of natural polyphenols and isoflavones. Molecules 21:708-723.

Vardin H, Tay A, Ozen B, Mauer L (2008). Authentication of pomegranate uice concentrate using FTIR spectroscopy and chemometrics. Food Chemistry 108(2):742-748.

Veličković JM, Kostić DA, Stojanović GS, Mitić SS, Mitić MN, Randelović SS, Đorđević AS (2014). Phenolic composition, antioxidant and antimicrobial activity of the extracts from Prunus spinosa L fruit. Hemijska Industrija 68(3):297-303.

Vergani L, Vecchione G, Perego P (2018). Polyphenolic extract attenuates fatty acid-induced steatosis and oxidative stress in hepatic and endothelial cells. European Journal of Nutrition 57(5):1793-1805. 